\title{
The problem of optimal selection of activities carried out in major construction
}

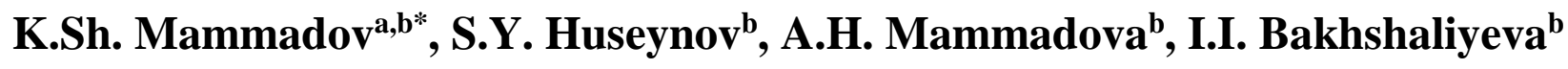 \\ ${ }^{a}$ Baku State University, Baku, Azerbaijan \\ ${ }^{b}$ Institute of Control Systems of Azerbaijan National Academy of Sciences, Baku, Azerbaijan
}

\begin{tabular}{|c|c|}
\hline $\begin{array}{ll}\text { A R T I C L E I N F O }\end{array}$ & A B S T R A C T \\
\hline $\begin{array}{l}\text { Article history: } \\
\text { Received } 22.10 .2021 \\
\text { Received in revised form } 03.11 .2021 \\
\text { Accepted } 10.11 .2021 \\
\text { Available online } 29.12 .2021\end{array}$ & $\begin{array}{l}\text { The article considers the issue of optimal selection of activities } \\
\text { required for the construction or restoration of residential areas, } \\
\text { industrial enterprises, monuments, etc. An economic } \\
\text { mathematical model of this problem is built. }\end{array}$ \\
\hline $\begin{array}{l}\text { Keywords: } \\
\text { Construction equipment and materials } \\
\text { Construction and installation work } \\
\text { Priority of activities }\end{array}$ & \\
\hline
\end{tabular}

\section{Introduction}

The drafting of a major construction plan in various areas is one of the important issues in the development of each country's economy. Various construction sites here include the construction or restoration of schools, hospitals, residential buildings, industrial and foodservice facilities, and so on.

Major construction means the construction, expansion and reconstruction of an existing enterprise or a new building, as well as the technical re-equipment and improvement of technology of an existing enterprise or organization that requires construction.

In particular, given the current conditions, it is necessary to carry out various types of construction work. For instance, in the liberated regions, lists should be drawn up for the construction and restoration of houses, industrial and foodservice facilities, and monuments.

The drafting of such plans or projects can be carried out by public or private companies.

This article considers the issue of optimal selection of the list of measures for the construction or restoration of such facilities and its mathematical model. Here, the principles of building economic-mathematical models from [1, pp.230-237; 2, p.304; 3, pp.154-164] are used. It should be noted that brief information about this work is given in [4, pp.319-321].

\section{Problem statement}

Suppose that there are many construction activities to be carried out. Naturally, different types of equipment, materials, their volume or quantity, the amount of demand for each of them, the total funds allocated for these works (resource, cost, raw materials, etc.), the priority of each construction

\footnotetext{
${ }^{*}$ Corresponding author. ayla79a@gmail.com ( A.H. Mammadova), bakshaliyeva.irada@gmail.com (I.I. Bakhshaliyeva).

E-mail addresses: knyaz.mamedov@yahoo.com (K.Sh. Mammadov), saqif.huseynov@gmail.com ( S.Y. Huseynov), 
activity, etc. should be known.

Obviously, after we get all this information, we need to compile a list of construction activities for a certain planning period so that the effect (income, earnings, profit, etc.) of the selected facilities is maximized within the existing constraints.

For this purpose, we adopt the following notation.

$\Omega-$ the totality of all major construction activities,

$J-$ the totality of all types of materials,

$\omega-$ the totality of all construction and installation works,

$R-$ the totality of equipment,

$V_{j q}$ - the amount of the construction and installation works of $j$-th type when carrying out the $q$-th activity, $(q \epsilon \Omega, j \in \omega)$. If the $j$-th, $(j \epsilon \omega)$ type of construction and installation work is not required when carrying out the activity of the $q$-th type, $(q \in \Omega)$, then $V_{j q}=0$.

$G_{r}$ - is the limit amount of equipment of the $r$-th type, $(r \in R)$,

$a_{i j}$ - the amount of expense per unit of the material of $i$-th type, $(i \in J)$ in the carrying out the $j$-th, $(j \in \omega)$ type of work,

$m_{i}$ - the total funds (resource) allocated by the external organization in major construction for the amount of the materials of the $i$-th type, $(i \in J)$.

$G_{r q}$ - the demand for the $r$-th type of equipment, $(r \in R)$, during the implementation of the $q$ th type $(q \in \Omega)$ of activity, If the equipment of the $r$-th type, $(r \in R)$ is not required when carrying out the activity of the $q$-th type, $(q \in \Omega)$, then $G_{r q}=0$.

$K$ - the total cost allocated to the major construction site during the planning period,

$C_{q}$ - the value of the priority of the $q$-th activity $(q \in \Omega)$,

In this problem, it is required to compile a list of implementation activities of construction projects under the given information and constraints, such that the necessary constraints are satisfied, with the maximum effect (income, earnings, profit, etc.) from their use.

To build a mathematical model of the problem, let us accept the unknowns $x_{q}$ as follows.

$$
x_{q}=\left\{\begin{array}{l}
1, \text { if activity } q \text { is carried out }, \\
0, \quad \text { otherwise. }
\end{array}\right.
$$

The general assessment for approved activities within the adopted notation is as follows.

$$
\sum_{q \in \Omega} c_{q} x_{q}
$$

Capital investment for repair and construction works:

$$
\sum_{q \in \Omega} \sum_{j \in \omega} V_{j q} x_{q}
$$

The demand (cost) for the acquisition of equipment is calculated by the formula

$$
\sum_{r \in R} \sum_{q \in \Omega} G_{r q} x_{q}
$$

Then the required total cost should be written as a condition such that it does not exceed the allocated $K$ capital investment:

$$
\sum_{q \in \Omega} \sum_{j \in \omega} V_{j q} x_{q}+\sum_{r \in R} \sum_{q \in \Omega} G_{r q} x_{q} \leq K
$$

The total funds required for the purchase of the $r$-th type of equipment: 


$$
\sum_{q \in \Omega} G_{r q} x_{q}, \quad(r \in R)
$$

It is clear that the total cost of purchased equipment should not exceed the allocated limit $G_{r}$. That is, the inequality

$$
\sum_{q \in \Omega} G_{r q} x_{q} \leq G_{r},(r \in R)
$$

must be satisfied.

On the other hand, the amount of basic construction materials should not exceed the given limit $m_{i}(i \in J)$. Then, this condition will take the following form:

$$
\sum_{q \in \Omega} \sum_{j \in \omega} a_{i j} V_{j q} x_{q} \leq m_{i}, \quad(i \in J)
$$

Here, the product $a_{i j} V_{j q}$ is the demand for the $i$-th type of material required when carrying out the activity $q$ for each $j$-th repair and construction work.

Thus, the mathematical model of the problem of optimal selection of the implementation of repair and construction facilities is as follows.

$$
\begin{gathered}
\sum_{q \in \Omega} c_{q} x_{q} \rightarrow \max , \\
\sum_{q \in \Omega} G_{r q} x_{q} \leq G_{r},(r \in R), \\
\sum_{q \in \Omega} \sum_{j \in \omega} a_{i j} V_{j q} x_{q} \leq m_{i},(i \in J), \\
\sum_{q \in \Omega}\left(\sum_{j \in \omega} V_{j q}+\sum_{r \in R} G_{r q}\right) x_{q} \leq K, \\
x_{q}=1 \vee 0,(q \in \Omega) .
\end{gathered}
$$

Suppose that $\Omega=\{1,2, \ldots, n\}$. Then denote

$$
a_{i q}=\sum_{j \in \omega} a_{i j} V_{j q}, \quad(i \in J ; q \in \Omega)
$$

And if we take $R=\left\{1,2, \ldots, m_{1}\right\}, J=\left\{m_{1}+1, m_{1}+2, \ldots, m_{2}\right\} m=m_{2}+1$, problem (1)-(5) will be as follows:

$$
\begin{gathered}
\sum_{j=1}^{n} c_{j} x_{j} \rightarrow \max , \\
\sum_{j=1}^{n} a_{i j} x_{j} \leq b_{i}, \quad i \in(R \cup J \cup\{m\})=\overline{1, m} \\
x_{j}=1 \vee 0, \quad(j=\overline{1, n}) .
\end{gathered}
$$

Here, the last inequality of system (7) is written as follows ${ }^{\wedge}$ 


$$
a_{m q}=\sum_{j \in \omega} V_{j q}+\sum_{r \in R} G_{r q}, \quad b_{m}=K
$$

Thus, the problem of optimal selection of activities for capital construction comes down to a Boolean programming problem of the type of (6)-(8). To solve it, it is possible to apply exact or approximate solutions known from the literature.

\section{Conclusion}

Considering the above, the following conclusions can be drawn:

- A model of optimal selection of necessary activities has been built for various construction works.

- The optimal amount of all materials, equipment, etc. required for construction has been determined within the given constraints.

- In particular, the proposed model can be used in large-scale construction, restoration and installation works in the liberated territories of Azerbaijan.

\section{References}

[1] Д.Б. Юдин, А.Д. Юдин, Экстремальные модели в экономике, Москва, “Экономика”. (1979) pp.230-237. [In Russian: D.B. Yudin, A.D. Yudin, Extreme models in economics, Moscow, Ekonomika].

[2] И.Х. Сигал, А.П. Иванова, Введение в прикладное дискретное программирование, Москва, Физматлит, (2007) p.304. [In Russian: I.Kh. Sigal, A.P. Ivanova, Introduction to applied discrete programming, Moscow, Fizmatlit].

[3] К.Ш. Мамедов, Исследование по целочисленной оптимизации (методы, алгоритмы и вычислительные эксперименты), LAP Lambert Academic Publishing, Germany. (2012) pp.154-164. [In Russian: K.Sh. Mammadov, Research on integer optimization (methods, algorithms and computational experiments)].

[4] К.Ш. Мамедов, С.Я. Гусейнов, А.Г. Мамедова, И.И. Бахшалиева, Задача составления оптимальных списков мероприятий по строительству, Science, Education, Innovation: Topical Issues and Modern, 4-5 October, N77, 2021, Tallin, Estonia. pp.319-321. [In Russian: K.Sh. Mammadov, S.Y. Huseynov, A.H. Mammadova, I.I. Bakhshaliyeva, The problem of compiling optimal lists of construction activities]. 